

\author{
Journal of Transport Literature \\ Vol. 8, n. 4, pp. 279-315, Oct. 2014 \\ Research Directory
}

JTL|RELIT

www.journal-of-transport-literature.org ISSN 2238-1031

\title{
Metodologia para estimativa de fluxos de carga a partir de dados secundários: uma aplicação em Belo Horizonte
}

[Methodology for estimating freight flows from secondary data: an application in Belo Horizonte]

\author{
Lílian dos Santos Fontes Pereira, Leise Kelli de Oliveira* \\ Federal University of Tocantins - Brazil, Federal University of Minas Gerais - Brazil
}

Submitted 4 Sep 2013; received in revised form 13 May 2014; accepted 8 Jun 2014

\begin{abstract}
Resumo
O bom planejamento dos fluxos de mercadorias no meio urbano requer o conhecimento da matriz Origem Destino de cargas. Esse estudo tem como objetivo geral propor uma metodologia para estimar fluxos de cargas a partir de dados secundários, empregando princípios de modelos baseados em atividades e avaliar sua aplicabilidade. Os métodos tradicionalmente utilizados para obtenção de uma matriz OD têm um custo elevado e dificuldades metodológicas de coleta de dados, inviabilizando, muitas vezes, sua atualização. A metodologia proposta se baseia nas variáveis localização, tipo de atividade, e variável explicativa do modelo de geração de viagens e compreende as etapas de definição da área de estudo, zoneamento, escolha dos segmentos econômicos, coleta e tratamento de dados secundários, geração de viagens, modelagem da distribuição e calibração. A metodologia foi aplicada em Belo Horizonte (MG), tendo como base de dados o Cadastro Municipal de Contribuintes de 2011. 0 modelo foi construído a partir dos princípios de Integração de Uso do Solo e Transportes, com aplicação do modelo TRANUS. Para calibração, foram utilizados dados oficiais do município e pesquisas de campo anteriores. A metodologia se mostrou aplicável, sendo obtida uma matriz OD estimada compatível com os dados de referência.
\end{abstract}

Palavras-Chave: logística urbana, fluxo de mercadorias, matriz OD, dados secundários, modelo de atividades.

\begin{abstract}
Good planning of freight flows in the urban environment requires knowledge of the freight Origin Destination matrix. This study aims to propose a methodology to estimate freight flow from secondary data, employing the principles of activity-based models and evaluate its general applicability. The methods traditionally used for obtaining OD matrix have a high cost and methodological difficulties in data collection, making impracticable its updating. The proposed methodology is based on the location, type of activity and the explain variable of the generation model and it consists of seven stages, including the definition of the study area, zoning, choice of economic segments, collection and treatment of secondary data, trip generation, distribution modeling and calibration. The methodology was applied in Belo Horizonte (MG), based on data from the Municipal Register Contributors from 2011. The model was built based on the principles of Integrated Land Use and Transport, applying the model TRANUS. For calibration, it was used official data from the municipality and previous research. The methodology proved being applicable, and it provided an estimated OD matrix compatible with the reference data.
\end{abstract}

Key words: city logistics, freight flow, OD matrix, secondary data, activity model.

*Email: leise@etg.ufmg.br.

\section{Recommended Citation}

Pereira, L. S. F. and Oliveira, L. K. (2014) Metodologia para estimativa de fluxos de carga a partir de dados secundários: uma aplicação em Belo Horizonte. Journal of Transport Literature, vol. 8, n. 4, pp. 279-315.

- JTL/RELIT is a fully electronic, peer-reviewed, open access, international journal focused on emerging transport markets and published by BPTS - Brazilian Transport Planning Society. Website www.journal-of-transport-literature.org. ISSN 2238-1031.

This paper is downloadable at dx.doi.org/10.1590/2238-1031.jtl.v8n4a11 


\section{Introdução}

O estudo desenvolvido tem como objetivo propor uma metodologia baseada em modelos de atividades, para estimar uma matriz OD de cargas, a partir de dados secundários do cadastro municipal de contribuintes e validar sua aplicabilidade por meio de um estudo de caso.

O transporte de carga eficiente tem papel significativo na competitividade econômica de uma área urbana e pode ser, em si mesmo, um elemento importante tanto em termos da renda criada, quanto no nível de emprego que mantém. Mostra-se, assim, fundamental para a sustentação do nosso estilo de vida, servindo à indústria e às atividades de comércio, que são essenciais à geração de riqueza (Dutra e Novaes, 2005).

Apesar disto, Dutra e Novaes (2005) apontam que, mesmo sendo necessário, o transporte de cargas dentro das cidades causa muitos transtornos à população, como congestionamentos, poluição, ruído, vibração, acidentes, entre outros. Por outro lado, a estrutura urbana e as medidas que têm sido tomadas para minimizar os problemas reduzem a acessibilidade e diminuem a eficiência logística do sistema de transporte urbano de pessoas e mercadorias. Isto resulta no aumento dos tempos de viagem, baixa qualidade do serviço e, em alguns casos, maior número de veículos do que o necessário. Para a autora, apesar do problema da movimentação de mercadorias na área urbana não ser novo, de uma maneira geral, não foi considerado no planejamento urbano das cidades.

A falta de informação tornou difícil estimar impactos das mudanças políticas para entender e planejar os movimentos de mercadorias entre as regiões. Ambite et al. (2003) reforçam que com o aumento do fluxo de carga e crescimento do seu impacto, planejadores de transporte, gestores e operadores têm grande interesse em desenvolver melhores métodos de roteirização e monitoramento dos fluxos de carga e analisar o impacto causado por esses fluxos. No entanto, os métodos existentes de estimativa e análise dos fluxos de carga apresentam diversos problemas, seja relacionado à disponibilidade de dados, seja relacionado ao método propriamente.

O principal instrumento utilizado para o planejamento de transportes é a Matriz OrigemDestino (Matriz OD), para a qual se tem duas opções: desenvolver um método estimativo a 
partir dos dados disponíveis ou coletar os dados diretamente dos transportadores. As abordagens baseadas em entrevistas são dispendiosas, trabalhosas e demandam um tempo considerável de levantamento e tabulação de dados. Nesse contexto, este trabalho pretende-se avaliar a aplicação de uma metodologia para estimar uma matriz OD de cargas, a partir de dados socioeconômicos.

Existem métodos tradicionalmente utilizados no planejamento de transportes, empregados principalmente para estimar cenários futuros, sendo o principal deles o Modelo de Quatro Etapas. Este modelo clássico é representado como uma sequência de quatro submodelos: geração e distribuição de viagens, divisão modal e alocação de tráfego. A matriz OD é produto das duas primeiras etapas. O modelo tem foco diretamente na viagem, e menos nas relações de consumo por trás da necessidade de deslocamentos.

Outros modelos existentes são os Modelos de Atividades, Modelos de Integração Uso do Solo e Transportes e Modelos de Preferência Declarada. Os Modelos Integrados de Uso do Solo e Transportes, além da relação com as atividades, buscam identificar os impactos das alterações de uso do solo no sistema de transportes e vice-versa, em uma relação cíclica, de modo a prever padrões de desenvolvimento do solo urbano e dos sistemas de transporte. Partindo-se desses modelos, é possível estabelecer uma relação para a movimentação de cargas, visto que existe uma relação de produção e consumo que estabelece uma demanda de fluxo de mercadorias, antecedente ao transporte propriamente dito. $\mathrm{O}$ transporte de cargas ocorre então para satisfazer essa demanda, e se relaciona diretamente com a localização das unidades de produção e de consumo, além das condições de transporte.

Para o desenvolvimento deste estudo, parte-se da hipótese de que a matriz OD de cargas pode ser gerada a partir da aplicação de um Modelo Integrado de Uso do Solo e Transportes, baseado em atividades, que converte fluxos econômicos em fluxos de transporte, associado à etapa tradicional de geração de viagens.

A contribuição deste trabalho justifica-se pela necessidade de investigação de métodos alternativos para obtenção de dados capazes de orientar o planejamento e a tomada de decisão em relação ao transporte urbano de mercadorias. A escassez de dados que auxiliem o planejamento do transporte de cargas em meio urbano impõe uma limitação ao desenvolvimento de políticas públicas mais eficientes em relação à Logística Urbana. Essa 
escassez se deve, principalmente, ao custo elevado e às dificuldades operacionais de coletar os dados em pesquisas de campo, como tradicionalmente é feito. Nesse sentido, o estudo desenvolvido agrega também uma contribuição social ao buscar alternativas para a aquisição de dados e estimativa de uma matriz OD de cargas com um grau de confiabilidade considerável, ampliando as ferramentas do planejamento de transportes.

Além disso, o estudo avalia e explora a utilização do modelo integrado baseado em atividades, denominado TRANUS, mais comumente utilizados para análises do transporte de pessoas, para estimar o fluxo de cargas, contribuindo academicamente para o avanço dos modelos integrados. Entre as principais aplicações do modelo Swindon/Inglaterra (Pagliara et al., 2009), Aveiro/Portugal (Bandeira et al., 2011), Sapporo/Japão (Vichiensan et al., 2003) e Oregon/EUA (Parsons, 1999) apenas a aplicação de Oregon modelou também o transporte de cargas, tendo como base de dados o fluxo econômico entre os setores industriais que compunham o modelo.

A metodologia proposta neste trabalho, parte do pressuposto de que se conhecendo três variáveis (localização, atividade, e variável explicativa do modelo de geração de viagens), obtidas a partir de bases secundárias, pode-se estruturar um modelo para estimativa de fluxos de um determinado canal de distribuição. A proposta baseia-se no princípio dos modelos de atividades, que focam as análises nas atividades motivadoras das viagens. Assim, identifica-se as atividades que representam as relações de produção e consumo que se pretende analisar, a partir das quais viagens são geradas. Uma vez identificadas as relações de consumo, é necessário localizar geograficamente os pontos nos quais essas atividades são realizadas, sendo também os pontos de atração e geração de viagens.

O tratamento da base de dados permite classificar os estabelecimentos, distinguindo os pontos de produção (geradores de viagens) e os pontos de consumo (atratores de viagens), a partir da descrição de sua atividade. Essa distinção deve ser feita a partir do entendimento da cadeia logística do tipo de carga estudado, considerando quais estabelecimentos atuam como atratores de viagens, produtores e ainda aqueles que atraem e produzem viagens.

Uma vez classificados e localizados espacialmente esses estabelecimentos, são calculadas as viagens atraídas e produzidas em cada área definida pelo zoneamento, chamadas zonas. Esse cálculo considera a área do estabelecimento como variável explicativa da geração de viagens, 
em função da base de dados utilizada dispor dessa informação. Este estudo sugere a utilização de equações previamente conhecidas, de acordo com o tipo de carga. No caso de não existirem tais equações para o tipo de carga analisado, ou não se ajustarem bem às características observadas na área de estudo, deve ser realizada uma pesquisa com varejistas e atacadistas do segmento estudado, a fim de relacionar a área do empreendimento, ao número de viagens atraídas ou produzidas pelo tipo de estabelecimento. Ressalta-se que a etapa de geração de viagens pode ser calculada com o emprego de Modelos Integrados de Uso do Solo e Transportes, nos quais são identificadas relações econômicas entre os setores de produção e consumo, devido a demandas estabelecidas entre os setores, e a partir dessas relações são calculadas as viagens. Nesse estudo, optou-se por calcular as viagens em uma etapa separada, a fim de se ter maior controle dos parâmetros.

Tradicionalmente, finalizada a etapa de geração de viagens, é aplicado um dos diversos modelos de distribuição das viagens, dos quais se destacam o Gravitacional, Fratar e Máxima Entropia. No entanto, com o intuito de agregar ao estudo os conceitos dos modelos baseados em atividades, partindo-se do princípio das relações de demanda e minimização dos custos, a etapa de distribuição foi feita utilizando-se o software TRANUS@ (Integrated Land Use and Transport Modeling System), que relaciona a localização de atividades no espaço, uso do solo e o sistema de transporte. Para realização dessa etapa, é necessário modelar a rede viária, com atributos de capacidade, velocidade, sentido de circulação, custos envolvidos e demais atributos que caracterizem geometricamente a malha viária.

O cálculo de geração de viagens realizado separadamente simplifica os parâmetros a serem introduzidos no software, visto que os dados de entrada representam as viagens produzidas e atraídas em cada zona, a relação entre os setores de produção e consumo é unitária, bem como o fator de volume que relaciona os modelos de Uso do Solo e de Transportes.

A fase final do método proposto consiste em calibrar a matriz calculada de acordo com volumes reais identificados em contagens volumétricas. $\mathrm{O}$ procedimento consiste em alocar a matriz encontrada em algum software que permita fazer essa calibração de volumes por link, como, por exemplo, o Transcad@.

Como resultado da aplicação da metodologia para a região central de Belo Horizonte foi obtida uma matriz OD do fluxo de cargas, cujo índice de correlação com os dados de 
referência foi 0,81 , indicando tratar-se de uma ferramenta válida para gerar informações preliminares e subsidiar o Planejamento Urbano e de Transportes em municípios que tenham o Cadastro Municipal de Contribuintes.

O detalhamento deste trabalho é apresentado em quatro seções: A Seção 1 trata do estado da arte sobre modelagem de fluxos de carga. Inicialmente é abordado o problema urbano dos deslocamentos de carga, para a qual o planejamento se mostra mais complexo e mais carente de ferramentas eficientes. Em seguida, trata-se especificamente das matrizes OD, instrumento fundamental para o planejamento de transportes. A Seção 3 apresenta a metodologia proposta para a modelagem de uma matriz OD a partir de dados secundários, partindo de modelos clássicos de geração, e baseada no princípio dos modelos de atividades. A Seção 4 apresenta os resultados da aplicação da metodologia ao município de Belo Horizonte e apresenta os resultados encontrados. Finalmente serão apresentadas as conclusões sobre o trabalho, retomando os objetivos inicias, descrevendo as dificuldades, limitações e potencialidades do estudo, e apontando recomendações para trabalhos futuros.

\section{Estado da arte sobre modelagem de fluxos de carga}

O entendimento da demanda por um produto ou serviço é de importância fundamental para o planejamento de transportes, destacando-se o dimensionamento da capacidade de empreendimentos, a análise da viabilidade de projetos de investimentos, o estabelecimento de estratégias de competição entre empresas, a política da escolha modal, as decisões das ações governamentais para alocação de recursos que venham possibilitar melhorias para o usuário do serviço, entre outros.

O principal elemento de planejamento utilizado em transportes é a Matriz OD, cujas pesquisas necessárias à sua elaboração são dispendiosas, trabalhosas e demandam um tempo considerável de levantamento e tabulação de dados. De acordo com Souza et al. (2010), a complexidade de modelar a demanda de transporte de carga surge da necessidade de considerar a existência de diversas dimensões (diferentes tipos de carga, volumes, pesos e volume de viagens) sob o controle de diferentes tomadores de decisão (embarcadores, transportadores, motoristas e despachantes) que interagem em um ambiente dinâmico. 
O estudo da demanda pode seguir diferentes abordagens conforme seus objetivos, natureza dos dados obtidos e disponibilidade de recursos humanos, financeiros ou até mesmo computacionais. Uma etapa fundamental é caracterizar um modelo para prever respostas às mudanças, inclusive para os atributos dos sistemas de transporte.

Ao se modelar a demanda, o primeiro passo é definir o objetivo que se quer alcançar, e de acordo com esse objetivo a abordagem pode ser: preditiva, que apenas procura a melhor estimativa da demanda futura; explicativa, que melhor enfoca os fenômenos observados no mercado, captando a influência das variáveis mais significantes, como preço ou renda; ou mesmo uma abordagem na esfera de interesse do planejamento, entendida como o estudo das políticas econômicas ou tecnológicas, onde se definem quais variáveis podem ser alteradas, sendo estas denominadas de "instrumento", medindo-se os efeitos de seus movimentos sobre as variáveis que se quer atuar, denominadas de "alvo" (Melo e Campos, 2003).

Para prever a demanda há a necessidade de se selecionar o método de análise, julgar a adequabilidade do modelo, ajustar observações discrepantes, e até mesmo fazer uma análise de sensibilidade dos resultados.

Souza e D'Agosto (2013) analisaram 44 trabalhos empregando o modelo quatro etapas para estudo de fluxos de carga, considerando fluxos de unidade de massa ou de veículos, e concluíram que o modelo pode ser empregado de forma parcial ou integral, sem limitação do tipo de carga ou modo de transporte.

Para a grande maioria dos modelos de demanda por carga, segundo Ortúzar e Willumsen (1990), as previsões aplicadas na prática são do tipo agregadas. Eles seguem o modelo de quatro etapas, com algumas adaptações específicas para carga. Para cada uma das etapas, os autores ressaltam:

- Geração de Carga - a geração de carga depende basicamente do nível de agregação e dos tipos de produtos considerados, tanto na produção como na atração, ; nas áreas urbanas, a regressão linear múltipla por zona é frequentemente usada para se obter medidas mais agregadas, e a demanda pode ser associada com a capacidade de armazenagem ou com o total de área construída para esta finalidade em cada zona;

- Distribuição de carga - muitos estudos urbanos aplicam o método de fator de crescimento para obter as matrizes de movimentação de bens. Além deste método, as 
técnicas agregadas são mais usadas nesta área, como o modelo gravitacional e a programação linear;

- Escolha Modal - esta é essencialmente a decisão do expedidor sobre qual o meio de transporte que será escolhido para fazer a entrega dos bens em seus destinos. Quando modelada a um nível agregado, a escolha modal é frequentemente considerada adotando-se uma formulação Logit Multinomial, também baseada em custos generalizados, onde essas decisões dependem das taxas praticadas pelos transportadores, que em troca dependem dos volumes a serem movimentados entre cada par OD.

- Alocação da carga - esta é a decisão do transportador sobre a escolha da melhor rota para transportar os bens da origem ao destino. A consideração de restrições de capacidade mostra-se relevante na maioria das situações urbanas. Para estas situações, podem ser discutidos quais os diferentes tipos de veículos que devem ser modelados nas diferentes rotas. As características dos veículos e das cargas transportadas influenciam na alocação como por exemplo no caso de se necessitar vencer trechos de aclive, onde o VLC (veículo leve de carga) pode ter menos dificuldades do que os caminhões pesados; ou no caso dos veículos que transportam bens perecíveis, que poderiam prioritariamente adotar rotas com tempos minimizados, o que já não se faz necessário para aqueles veículos que carregam suprimentos volumosos não perecíveis. O uso de métodos multiclasses de designação pode então ser adequado para competir com os diversos conceitos de custo.

A geração de viagens corresponde à etapa do processo de planejamento dos transportes que está relacionada com a previsão do número de viagens de pessoas ou veículos. Pesquisadores têm estudado a geração de viagens ao longo dos anos, para segmentos distintos, e existe uma grande variedade de modelos, cada um com suas limitações e vantagens características:

- Fluxos de viagens de Shopping Centers: Christiansen (1979); Gasparini (2008);

- Fluxos de viagens de lojas comerciais: Melo e Campos (2003);

- Fluxos de viagens no segmento bares e restaurantes: Silva e Waisman (2007);

- Fluxos de viagens de carga gerado por indústrias: Zonnenberg (1989);

- Fluxos de viagens por uso de solo: Chatterjee et al. (1979); Zavattero e Weseman (1993); Tadi e Baldach (1994); Marra (1999); Lawson et al. (2012); 
- Modelos gerais para geração de carga urbana: Ogden (1992); Iding et al. (2002); Munuzuri et al. (2009).

Além desses estudos, o trabalho desenvolvido por Holguín-Veras et al. (2011) analisou fatores que questionam as práticas atuais, que buscam relações diretas entre algumas variáveis e a geração de viagens. Os autores concluem que a precisão dos modelos de geração de carga e de geração de viagens de carga depende da consistência entre a estrutura do modelo e os reais padrões de geração de carga e a geração de viagens de carga, o grau de heterogeneidade interna da agregação uso econômico / terra usada para estimar o modelo e a adequação do procedimento de agregação espacial utilizada para obter as estimativas de geração de carga e a geração de viagens de carga. Isto significa que não é geralmente correto assumir a proporcionalidade entre geração de viagens de carga e tamanho do negócio, e que o uso de taxas constantes poderia ser problemático. Por exemplo, apenas 18\% dos setores da indústria em Nova York exibem taxas constantes de geração de viagens de carga por empregado.

A falta de modelos de demanda de carga apropriados pode ser explicada, em parte, pela ausência de um equilíbrio adequado entre o conhecimento, os modelos e os dados. Para entender os motivos, é importante apresentar três axiomas. O primeiro é de que "o conhecimento do funcionamento do sistema é necessário para a criação de modelos explicativos do seu comportamento", uma vez que não é possível desenvolver bons modelos de um sistema que não é bem entendido. O segundo axioma é que "os dados nem sempre equivalem ao conhecimento, como o último requer teorias que explicam o funcionamento do sistema". O terceiro axioma é que "a coleta de dados é mais eficaz quando é informada pelo conhecimento sobre o sistema, e os requisitos dos modelos que eles apoiariam”. Estes axiomas sugerem que antes do desenvolvimento do modelo e de empenhar esforços na coleta de dados, deve-se tentar obter conhecimento sobre o sistema em estudo (Holguín-Veras et al., 2011).

Ao estudar o modelo de geração de viagens de carga, é importante fazer uma distinção clara entre a geração de demanda, por exemplo, toneladas, e a geração de tráfego, por exemplo, viagens. Uma série de estudos tem identificado variáveis que explicam a geração de viagens de carga. As variáveis identificadas são: o uso do solo; atividade econômica, o emprego, tipo de mercadoria, linha de negócio, e uma área de criação; segmento da indústria tipo de mercadoria, transportada e emprego, o emprego total, área bruta de construção, e escritório 
não emprego. Outros estudos produziram taxas de viagem para: diferentes tipos de uso do solo e / ou tipos de veículos, instalações especiais, e armazéns. No entanto, o modelo mais utilizado é uma taxa de geração de viagens de carga constante como função de uma única variável independente (por exemplo, emprego, área). Lamentavelmente, a maioria destas taxas foi calculada sem testar a significância da variável independente utilizada, ou a validade da sua forma funcional (Holguín-Veras et al., 2011).

A etapa de distribuição de viagens tem o objetivo de distribuir as viagens calculadas na etapa de geração entre as áreas de estudo. Inicialmente, procura-se entender os fatores que influenciam no volume de viagens que ocorrem para cada destino. Posteriormente, se deseja saber como as variáveis influem na distribuição.

Existem três tipos de modelos mais utilizados para a distribuição de viagens, sobretudo para a estimativa de uma matriz futura, a partir de dados já conhecidos para a situação atual, sendo baseados em fatores de crescimento, gravitacionais e entrópicos, apresentados por Kawamoto (2008):

- Fatores de crescimento: Os modelos baseado em fatores de crescimento são utilizados para previsão de uma matriz futura e não se preocupam em explicar completamente a distribuição, no entanto são bastante utilizados na prática, devido, principalmente, à sua simplicidade.

- Gravitacionais: Em 1885, estudando o fluxo de migrantes entre Europa e EUA, Ravenstein observou que o número de pessoas que se movimentam entre quaisquer pares de cidades parecia ser proporcional ao tamanho delas e inversamente proporcional à distância entre elas. Em 1891, Lille sugeriu algo parecido ao estudar a rede de transporte ferroviário alemã. Foi apenas na década de 1950, no entanto, que o modelo tomou a forma conhecida atualmente.

- Entrópicos: Os modelos entrópicos são obtidos através de analogia com a física dos gases, em que uma determinada distribuição de viagens é definida como sendo um estado do sistema, adotando as seguintes hipóteses: (i) a probabilidade de ocorrer uma determinada distribuição é proporcional ao número de maneiras possíveis de se obter essa distribuição e, (ii) se um determinado estado persiste, é porque a probabilidade de sua ocorrência é máxima. 
Em geral, modelos de transporte estimam o fluxo de veículos na rede como função da distribuição espacial da atividade econômica, demanda por interação espacial, custos de transporte e capacidade da rede. Uma grande variedade de modelos foi desenvolvida, a maioria com foco exclusivo na movimentação urbana de passageiros. A movimentação de cargas é tipicamente modelada como um problema inter-regional (Ambite et al., 2003).

Os modelos utilizados para simular a demanda de cargas em escala nacional derivam da integração entre dois níveis (Cascetta, 2001): (i) modelos macroeconômicos que simulam a quantidade e a distribuição espacial dos bens comercializados entre as várias zonas, produzindo a Matriz OD e (ii) modelos que simulam a divisão modal e escolha de rotas em redes viárias representativas do serviço de transportes.

Um dos primeiros estudos sobre a movimentação urbana de cargas foi feito por Ogden (1992), que propôs modelos para gerenciar e controlar o transporte urbano de cargas. O autor também apresentou os primeiros resultados de estudos de casos em várias cidades do mundo, e identifica duas principais abordagens derivadas do modelo de quatro etapas (geração de viagens, distribuição de viagens, divisão modal e alocação de tráfego), ao se modelar a demanda por viagens de carga: modelos baseados em mercadorias e modelos baseados em viagens.

Os modelos baseados em mercadorias que consideram que o sistema de carga está basicamente relacionado com o movimento de mercadorias, podendo ser modelado diretamente. Seu estado da arte se baseia numa abordagem de modelagem sequencial (geração, distribuição, divisão modal e alocação). No entanto, uma alternativa é o uso de uma abordagem de estimativa direta, que agrupa os estágios de geração, distribuição e divisão em um único passo. As viagens de caminhão são derivadas da movimentação de mercadorias, através de um modelo de carregamento de veículos, e o resultado do modelo é a alocação de viagens de caminhão na malha viária. Os modelos baseados em viagens que estimam diretamente a atividade "viagem de caminhão". São identificadas três subcategorias: uma abordagem de modelagem sequencial, uma abordagem de estimativa direta (similares àquelas dos modelos anteriores) e uma abordagem de geração de tráfego de caminhão, que estima o número de viagens de caminhão geradas em um local ou área. 
Os modelos de atividades, por sua vez, reconhecem a existência de complexas interações entre a participação em atividades e o padrão da viagem. Este tipo de modelo, com ênfase na participação em atividades e nos seus padrões de realização, pode fornecer informações sobre o modo como os indivíduos e os domicílios alteram esta participação (atividades realizadas, modos de viagem, etc.) em resposta à determinada política de transporte e/ou de ocupação do solo, o que permite prever com mais precisão a dinâmica urbana da cidade.

Os modelos integrados buscam incorporar a antiga percepção de que o uso do solo também é afetado pela oferta de transportes. Esta retroalimentação indica que ambos estão mutuamente interligados (os modelos convencionais têm apenas o efeito direto). Os modelos integrados exploram a interação entre transportes, localização de atividades e uso do solo. Como ressalta De La Barra (2012) em modelos tradicionais, o uso do solo é definido exogenamente, e a partir dessa localização das atividades definem-se os fluxos, deslocamentos e a demanda por transportes. No modelo integrado, o uso do solo também é modelado endogenamente, sendo afetado pela política de transportes, e também a afetando, numa interação em ciclos até atingir-se um equilíbrio.

Dentre os modelos integrados, ressalta-se o TRANUS, desenvolvido por Tomas de La Barra em 1982 e aprimorado continuamente até a atualidade. Entre as principais aplicações desse modelo, cita-se:

- Swindon - com objetivo de modelar o desenvolvimento do solo, crescimento urbano e impactos nos fluxos de transporte da cidade em cenários futuros, com diferentes políticas de ocupação das áreas centrais. A simulação permitiu estimar as regiões da cidade com maior crescimento da população, do número de empregos e da área construída, além de apontar as vias com maior crescimento no volume de tráfego. (Pagliara et al., 2009)

- Aveiro - procurou simular os fluxos internos da cidade e estimar a emissão de poluentes por zona. Bastante focado nesse aspecto ambiental, a modelagem apresenta uma formulação mais simplificada, com apenas dois setores econômicos (básico e serviços), um setor de população e uma única categoria de transporte. A calibração do modelo foi feita comparando os volumes alocados na rede e dados de contagem 
volumétrica e revelou um $\mathrm{R}^{2}=0,2113$ no gráfico de dispersão entre os volumes calculados pelo modelo e os verificados em campo. (Bandeira et al., 2011)

- Sapporo - pretendia estimar os impactos da construção de uma nova linha de metrô no aglomerado urbano. Os pesquisadores verificaram uma tendência de maior crescimento populacional e de empregos no entorno das estações, ao melhorar o acesso e a mobilidade das áreas adjacentes à linha de metrô inserida no modelo. Nessa aplicação, o uso do solo também foi modelado, permitindo estimar a valorização imobiliária. Com um grau de detalhamento maior, a calibração desse modelo foi feita comparando-se a matriz OD real e a gerada pelo software, alcançando um $\mathrm{R}^{2}=0,6116$. (Vichiensan et al., 2003)

- Oregon - o modelo fez uma divisão mais detalhada dos setores de atividade econômica, com o estabelecimento de doze setores de emprego industrial. Foi estabelecida uma matriz de relações de consumo entre empregos industriais, proporcionais aos volumes de insumos demandados por cada setor da indústria. (Parsons, 1999)

A aplicação de um modelo baseado em atividades para o estudo das demandas de transporte de carga se mostra bastante interessante, visto que é possível estabelecer relações de consumo bastante explícitas, em que há um setor produtor e um setor consumidor, bem definido e espacialmente localizado para cada tipo de carga. 


\section{Metodologia}

A metodologia foi dividida em sete etapas que serão detalhadas em seguida, baseado no fluxograma apresentado na Figura 1.

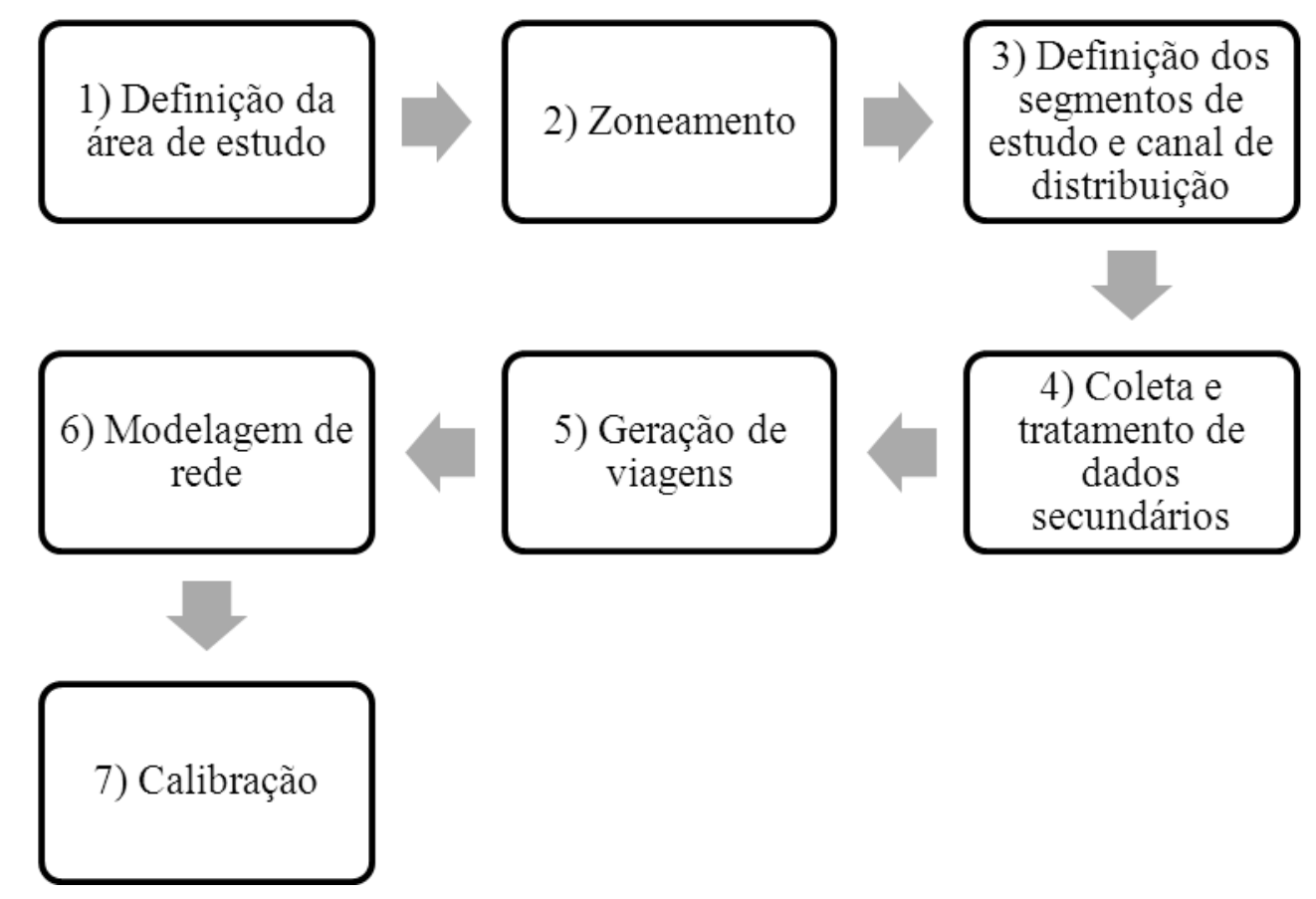

Figura 1 - Etapas sequenciais da metodologia proposta ${ }^{1}$

\subsection{Definição da área de estudo e área de planejamento}

A primeira etapa do estudo consiste na definição das áreas de planejamento e de estudo, que compreende a área onde serão coletados os dados secundários necessários para o modelo. A área de estudo deve ter uma abrangência tal que inclua as localidades com relações diretas com a área de planejamento.

A área de planejamento corresponde à área na qual se pretende avaliar impactos e propor medidas de intervenção. No caso desse estudo, a seleção da área de planejamento considerou a disponibilidade de dados de OD atualizados, avaliados por pesquisa de campo, para que se pudesse comparar com os resultados da metodologia proposta, e analisar sua validade.

\footnotetext{
${ }^{1}$ Fonte: Autores
} 
Diversos fatores podem interferir na escolha da área de estudo, sendo essa de maior abrangência que a área de planejamento em si. Em geral, considera-se uma área no entorno, que sofre ou exerce influência sobre a área de planejamento, devendo ser estudada para sustentar as observações feitas para a área de planejamento.

\subsection{Zoneamento}

Após definidas as áreas de estudo e planejamento, esta deve ser dividida em zonas, com características semelhantes, servindo de unidade base para a coleta de dados. Nguyen-Luong (2008) destaca a importância de que o zoneamento adotado seja compatível com os dados existentes e com o nível de desagregação pretendido.

Além disso, Parsons e Urban Analytics (1999) destacam a importância dos limites definidos para as zonas serem compatíveis com divisões oficiais, preferencialmente com as unidades básicas de coleta do censo, uma vez que podem ser agregadas sem perda de informação. $\mathrm{O}$ zoneamento deve ser compatível com a escala da análise pretendida, local, metropolitana ou regional. Para aplicação em planejamento de transportes, recomenda-se ainda, que as zonas compreendam áreas com acesso bem definido, respeitando o sistema viário principal.

\subsection{Definição dos segmentos de estudo e canal de distribuição}

O setor de cargas apresenta uma diversidade muito grande de produtos, e a rotina e característica das atividades logísticas variam em função da mercadoria transportada. Uma vez que se pretende estimar uma matriz $\mathrm{OD}$, torna-se necessário definir o tipo de carga, ou segmento, a ser estudado. Para este estudo adotou-se como critério de escolha, a representatividade do segmento, em termos de volume, no total de cargas circulantes na cidade.

Uma vez definido o tipo de carga a ser estudado, é necessário conhecer seu canal de distribuição, pois os dados devem ser classificados de forma compatível com esse canal, como será descrito a seguir. 


\subsection{Coleta e tratamento de dados}

A disponibilidade de dados consistentes é fundamental para o desempenho do modelo proposto. Para aplicação da metodologia proposta, é requerida uma base de dados com no mínimo as seguintes informações:

- localização espacial dos estabelecimentos comerciais relacionados à cadeia logística do tipo de carga estudado;

- descrição sucinta das atividades desenvolvidas pelos estabelecimentos;

- variável explicativa utilizada no modelo de geração de viagens adotado.

Geralmente, os municípios trabalham com o Cadastro Municipal de Contribuintes de Tributos Mobiliários - CMC, que é o cadastro de pessoas jurídicas que exercem atividades no município. A descrição das atividades é compatível com o código CNAE (Classificação Nacional de Atividades Econômicas). Conforme o grau de organização da administração municipal, essa base de dados é bastante consistente, completa e atualizada, e além da descrição da atividade, contém informação sobre a área útil do estabelecimento, que é uma variável explicativa comumente usada em modelos de geração de viagens.

A base de dados precisa ser tratada de modo a agrupar os estabelecimentos de acordo com o segmento de carga envolvido na sua atividade, para posteriormente serem trabalhados os segmentos definidos para o estudo.

Uma vez realizado o agrupamento por segmento, deve ser feita a distinção entre os estabelecimentos que exercem atividades predominantemente de produção de viagens, e os estabelecimentos com atividades que atraem viagens. Devem-se considerar ainda aqueles que produzem e atraem viagens, do segmento de carga estudado. Após essa distinção, os dados devem ser agrupados em zonas, a fim de identificar os estabelecimentos de cada zona.

A análise desses dados permite identificar as principais zonas geradoras e receptoras de cargas do segmento em estudo, e estimar, a partir do conhecimento da área útil de cada estabelecimento, o número de viagens produzidas e atraídas.

Caso não exista base de dados disponível para toda a área de estudo, somente para a área de planejamento, podem ser necessárias pesquisas auxiliares, de menor porte que uma pesquisa OD convencional, para conhecer a dinâmica de distribuição de cargas em toda a área de 
estudo. Esse levantamento pode ser feito a partir de uma caracterização do uso do solo da região, buscando-se identificar principais áreas geradoras de viagens de transporte de carga, do segmento analisado.

\subsection{Geração de viagens}

Inicialmente foi proposta a realização de uma pesquisa para identificação de um volume médio de viagens produzidas e atraídas em cada zona. A pesquisa seria realizada por telefone, com estabelecimentos comerciais que trabalham com o segmento estudado. As perguntas do questionário buscavam relacionar o número de viagens produzidas e atraídas de acordo com o porte do empreendimento, representado pela área útil.

A realização dessa pesquisa requer apoio e envolvimento dos comerciantes e entidades representativas do setor para que se consiga uma amostra estatisticamente válida. Durante a realização desse trabalho não foi possível alcançar um número de entrevistas significativo, sendo adotada uma segunda alternativa.

A alternativa encontrada foi adotar modelos de geração de viagens de carga previamente estudados e reconhecidos na comunidade científica, cujas condições de contorno fossem mais semelhantes às condições do estudo a ser feito. Esses modelos são variáveis em função do segmento e localidade do estudo.

\subsection{Modelagem para distribuição de viagens}

Após a estimativa da geração de viagens procede-se a montagem da rede para etapa de distribuição. Nesse caso, foi adotado o modelo TRANUS. Segundo De La Barra (2012), o TRANUS é um modelo de simulação sobre a localização das atividades, uso da terra e dos transportes, que pode ser aplicado em escala regional e urbana. O TRANUS utiliza conceitos de microeconomia espacial, modelos gravitacionais, matriz insumo-produto, modelos de escolha discreta e utilidade aleatória e, pode ser entendido pela composição das seguintes fases: (i) Modelo de Atividades; (ii) Interface Atividades - Transporte; (iii) Modelo de Transporte; (iv) Interface de Transportes-Atividades; e, (v) Processo de Avaliação. A interação das fases é cíclica, como representado na Figura 2. Pode-se observar que a interação entre as atividades gera uma demanda por transporte, cujo equilíbrio determina a localização 
das atividades e, assim, o uso do solo e preços imobiliários. Isso ocorre devido ao fato das atividades requererem o solo para seu funcionamento, e o equilíbrio entre oferta e demanda de espaço imobiliário em cada zona é obtido através da flutuação dos preços.

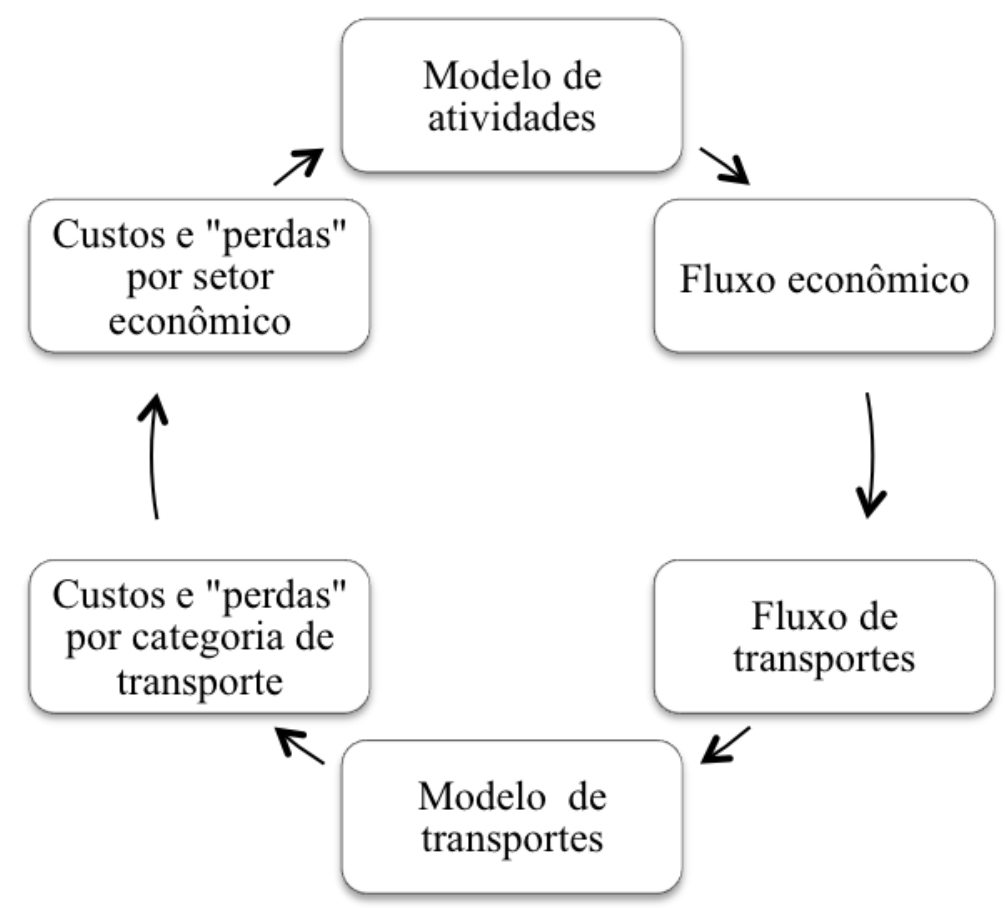

\section{Figura 2 - Ciclo do modelo de integração uso do solo e transportes ${ }^{2}$}

As alterações exógenas na política de regulação urbana (por exemplo, maior permissividade no uso do solo) ou na política de transporte (por exemplo, nova oferta, nova tarifa) alteram o equilíbrio e geram uma cadeia de eventos que realoca as atividades. $\mathrm{O}$ núcleo do modelo de atividades constitui um modelo espacial insumo-produto definido por setores econômicos e suas relações de produção e consumo.

A interação entre as atividades econômicas definidas no modelo gera uma matriz de fluxos. Os fatores de transformação, definidos ao especificar o modelo, determinam o número de viagens geradas pelos fluxos. Dessa transformação de fluxos econômicos em viagens determina-se a demanda por transportes, que é alocada levando em consideração as distâncias, custos, tempo de viagem, carregamento das vias, enfim, as características operacionais e físicas do transporte. Dessa distribuição parte-se para os impactos no uso do solo, com o desenvolvimento imobiliário sendo influenciado pelo transporte. O mercado imobiliário reage

\footnotetext{
${ }^{2}$ Fonte: os autores, baseado em De La Barra (2012)
} 
aos custos de transporte e às mudanças no preço do solo com realocação das atividades, reiniciando o ciclo até o sistema convergir para o equilíbrio.

No TRANUS $\odot$, os conceitos básicos de um modelo insumo-produto são generalizados e espacializados. O termo setor é mais amplo do que a versão tradicional, podendo representar setores tradicionais em que a economia se divide (agricultura, indústria, mineração, governo, etc.), fatores de produção (capital, terra e trabalho), bem como grupos de população, emprego, edificações, solo, etc., que fazem parte do sistema espacial.

Em princípio, qualquer setor exige insumos de outros setores. Dada a demanda final localizada de um ou mais setores, o modelo determina a produção induzida por funções de demanda, e a localiza espacialmente por funções de distribuição. Ao mesmo tempo, setores induzidos demandam insumos, gerando uma cadeia de produção e localização das atividades.

A partir das relações descritas acima, resultam transações econômicas, que dão origem a fluxos funcionais, quando a produção e o consumo ocorrem em diferentes áreas. Trata-se de fluxos de pessoas e bens ou serviços transportáveis, dos quais é derivada a demanda de transportes. É possível então simular diversos cenários, a partir da modificação da configuração do uso do solo, para avaliar o impacto sobre a demanda de transporte, ou avaliar o impacto que uma alteração no sistema de transporte pode provocar no uso do solo.

Após a etapa de distribuição, o software realiza as etapas de divisão modal e alocação de forma iterativa. Inicialmente o modelo define os caminhos disponíveis, considerando os modos de transporte a partir de uma zona de origem para um destino através dos links da rede viária. Isto significa que cada caminho não é simplesmente um caminho físico da rede de transporte, mas uma combinação de links e operadores por meio dos quais é possível realizar uma viagem entre uma origem e um destino. Assim, podem existir dois caminhos para seguir a mesma sequência de links, mas um operador ou uma combinação de diferentes operadores.

No processo de seleção de caminhos, o algoritmo calcula o custo generalizado dos caminhos, considerando os seguintes elementos para cada link / operador que faz parte da sequência do caminho:

- custo por unidade de tempo na ligação combinada link / operador para a categoria;

- custo por unidade de distância na ligação combinada link / operador para categoria; 
- custo de embarque no operador ou o link; pode ocorrer no início da viagem ou ao fazer uma transferência.

No processo de alocação, as viagens por categoria e modo são atribuídas aos caminhos disponíveis através de um modelo logit multinomial, usando a probabilidade de cada caminho.

O modelo calcula a probabilidade de escolha entre os caminhos disponíveis entre um par OD, considerando todos os custos envolvidos. Como os caminhos são sequências de ligações e modos, operadores ou rotas, as viagens se alocam a combinações ligação/operador ou ligação/rota em função dos custos generalizados das opções, compensados por seu grau de independência ou dependência. Isso significa que no TRANUS $\odot$, a divisão modal e alocação são realizadas simultaneamente em um só processo, que provou ter grandes benefícios, flexibilidade e consistência teórica, em comparação com os modelos convencionais baseados em processos separados de divisão modal logit combinados com alocação de equilíbrio. A combinação da repartição modal e alocação são equivalentes ao modelo logit realizado em cadeias de múltiplos níveis, e que são ajustadas automaticamente na rede.

Deve-se ressaltar que os fluxos de origem e destino são definidos no sentido da distribuição. Caso se deseja avaliar o movimento diário, deverá ser adotada uma matriz simétrica que corresponda ao número total de viagens/veículos nos dois sentidos do fluxo.

\subsection{Definição de parâmetros e calibração do modelo}

A calibração do modelo é feita a partir da verificação de convergência do modelo de atividades e do modelo de transportes. A convergência do modelo de atividades, que consiste na aproximação dos valores calculados endogenamente e aqueles fornecidos a partir da base de dados, é feita variando-se as elasticidades dos setores.

A elasticidade representa a capacidade de resposta do setor em relação às variações no preço. Quanto maior o valor da elasticidade maior a sensibilidade e reação do setor ao preço, e quanto menor a elasticidade, menor a reação ao preço.

Outro elemento que pode ser ajustado é a demanda intersetorial. A partir dela, serão calculadas as viagens, resultado da interação entre os setores. No caso, como as viagens foram 
previamente calculadas, e o quantitativo de cada setor se referem ao número de viagens produzidas e atraídas em cada zona, essa relação foi definida como igual a um, ou seja, cada unidade do setor produção gera uma unidade do setor consumo. Caso o dado de entrada não seja diretamente o número de viagens, o modelo oferece além da relação intersetorial, a opção de ajustar um fator de volume e de tempo, uma vez que o modelo de transportes trabalha com viagens diárias, ou de hora pico, e o modelo de atividades pode trabalhar com quilos de produto por mês. Esses fatores permitem igualar as unidades dos dois modelos. No caso desse estudo, os dois fatores são iguais a um, sendo que ambos os modelos trabalham com viagens diárias.

Existe ainda a possibilidade de ajustar a demanda da categoria de transporte e sua elasticidade. Quanto menor a elasticidade da categoria de transporte, mais viagens são geradas. Essa elasticidade pode ser modificada a fim de se considerar ocorrência de viagens internas na zona, que não são calculadas no modelo. Esses parâmetros são ajustados de modo a aproximar o número total de viagens ao número real observado.

A matriz final necessita ser calibrada a partir de dados de contagens volumétricas classificadas, realizadas nos pontos principais da rede viária. Esse tipo de procedimento é comumente utilizado na atualização de matrizes OD, e pode ser feito em diferentes softwares, como, por exemplo, o Transcad@.

\section{Resultados da aplicação da metodologia}

Esta seção apresenta os resultados da aplicação da metodologia, sendo suas subseções relacionadas com as etapas da metodologia.

\subsection{Definição da área de estudo e área de planejamento}

A escolha da área de estudo considerou diversos fatores, sendo o principal deles a existência de dados que permitissem avaliar os resultados do modelo proposto e verificar sua validade.

A área de estudo abrange o município de Belo Horizonte e região metropolitana, sendo que a análise de resultados se concentra na área central do município, considerada área de planejamento nesta aplicação. A escolha dessa área se deu em função da disponibilidade dos 
dados de campo coletados no estudo de Oliveira (2014), com o objetivo de caracterizar o transporte de cargas na área central de Belo Horizonte. A utilização desses dados como referência é importante para validar a metodologia proposta, permitindo uma comparação entre os dados de campo (Oliveira, 2014) e os resultados obtidos nesse trabalho.Definida a área central de Belo Horizonte como área de planejamento foco dessa aplicação, a área de estudo deve abranger os principais acessos do município e sua Região Metropolitana de Belo Horizonte, a fim de abarcar as origens dos fluxos de carga com destino à capital.

Para contextualizar a área de estudo, Belo Horizonte tem uma população de 2,4 milhões de habitantes, uma área de $331 \mathrm{~km}^{2}$ e o quarto maior Produto Interno Bruto (PIB) do Brasil, com cerca de 38,21 bilhões de reais e mais de 100 mil empresas (IBGE, 2010).

\subsection{Zoneamento}

A elaboração da matriz OD requer que o local estudado seja dividido em zonas, cujos limites devem seguir critérios coerentes com a dinâmica da cidade e com os efeitos que se deseja analisar. A etapa de zoneamento é muito importante nos processos de modelagem em transportes. Em geral, as unidades de coleta de dados em uma pesquisa OD são as áreas homogêneas, considerando aspectos socioeconômicos, físicos, urbanísticos entre outros. A utilização desse zoneamento é importante, pois permite a construção de uma série histórica ao longo dos anos. A última pesquisa OD de Belo Horizonte, publicada em 2002, adotou a divisão da Região Metropolitana de Belo Horizonte em 1.003 áreas homogêneas.

Um maior número de zonas minimiza as dificuldades de conectar os centroides à malha viária. Apesar dessa consideração, para aplicação da metodologia proposta foi necessário seguir alguns outros critérios para o zoneamento. Isso se deve ao fato da indisponibilidade de dados sobre o fluxo de carga dos segmentos escolhidos na escala das áreas homogêneas. Para os municípios vizinhos, a informação disponível era na escala de um município. Para Belo Horizonte, os dados se agrupavam em bairros, ainda assim, com algumas incompatibilidades de limites, sendo que nem todos os dados puderam ser utilizados para comparação. As áreas homogêneas de Belo Horizonte não respeitam criteriosamente os limites administrativos, o que dificulta a comparação dos dados. 
Ciente da necessidade de dados de referência, foram estabelecidos alguns pressupostos para o zoneamento da área de estudo:

- Zonas compatíveis com a coleta de dados da pesquisa de campo de referência, na área de planejamento;

- Zonas externas à área de planejamento com maior área, porém respeitando os principais acessos e o sistema viário estruturador;

- Os demais municípios da região metropolitana foram agregados de acordo com os principais eixos de acesso.

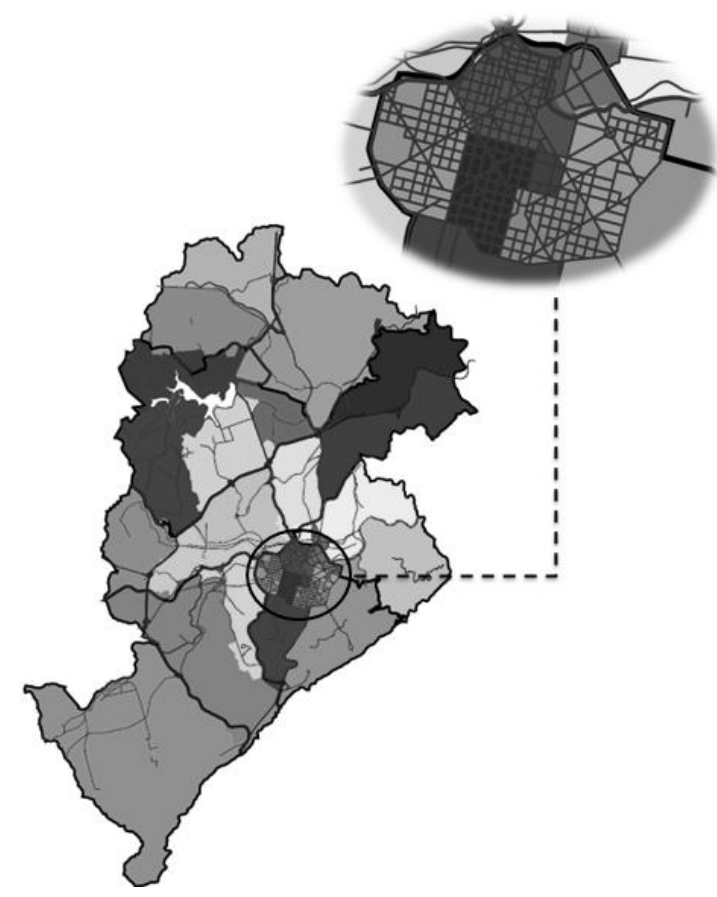

Figura 3 - Zoneamento proposto e sistema viário principal de Belo Horizonte com destaque para a área central ${ }^{3}$

A Figura 3 mostra a divisão do município de Belo Horizonte no zoneamento proposto, além do sistema viário principal e as vias arteriais. O zoneamento foi obtido a partir da agregação de bairros, buscando respeitar divisões administrativas pré-existentes, bem como as nove regionais do município. No total, seguindo esses critérios, foram delimitadas trinta zonas no município de Belo Horizonte e doze zonas na região metropolitana. Apesar do número de zonas ser bastante inferior ao número de áreas homogêneas, a conexão dos centroides à rede

\footnotetext{
${ }^{3}$ Fonte: Autores
} 
viária foi feita de forma bastante criteriosa, de modo a possibilitar várias alternativas de acesso, correspondentes aos caminhos reais, para cada zona.

\subsection{Definição dos segmentos de estudo, canal de distribuição e tratamento de dados}

Em função da representatividade no total de cargas circulantes em Belo Horizonte, foram selecionados para o estudo cargas dos segmentos alimentos e bebidas, que juntos correspondem a $42 \%$ do total de veículos transportadores na área central de Belo Horizonte, conforme Oliveira (2014).

Alimentos e bebidas são produtos perecíveis e frágeis, além de, em alguns casos, sazonais. Como ressalta Batista (2006), vários cuidados são requeridos, tanto nas operações logísticas que os envolvem, como na infraestrutura necessária para o seu transporte e armazenagem. Algumas características importantes são o alto volume de carga transportada; o giro dos estoques; o fluxo de movimentação bastante intenso, fatores atrelados a uma sazonalidade acentuada em determinados períodos do ano, sendo que, muitas vezes, os produtos recebidos no estoque não chegam a passar pelo processo de armazenagem, que são as chamadas operações de cross-docking, para diminuir o tempo das operações; elevado número de entregas diárias por veículo, chegando a trinta; cliente final diversificado, desde pequenos comerciantes até grandes redes atacadistas; produtos visados e, por este motivo, as cargas são na sua maioria das vezes rastreadas; veículos específicos para trânsito local, dentro de grandes cidades; necessidade de agilidade no atendimento/entregas, evitando desabastecimento do ponto de venda.

Em relação aos canais de distribuição, os segmentos de alimentos e bebidas adotam em grande parte os canais indiretos, com presença de atacadistas e varejistas como intermediários do sistema. Como aponta Almeida (1999), a utilização de canais indiretos justifica-se pelas especificidades do produto e da demanda. Trata-se de produtos de baixo valor unitário, com alto índice de substituição que tem uma demanda dispersa. A autora destaca que a estrutura de multicanais, incluindo o comércio direto entre indústria e varejista no segmento de alimentos tem aumentado, como uma estratégia de adaptação ao mercado. Porém, como foram abordados conjuntamente os segmentos de alimentos e bebidas, e essa tendência se difere nos dois segmentos, para efeitos da aplicação da metodologia, será considerado o canal de distribuição indireta. Cabe ressaltar que no canal indireto de distribuição os estabelecimentos 
atacadistas recebem a mercadoria proveniente das indústrias. No entanto, para efeito dessa aplicação, foi dado enfoque à distribuição entre atacado e varejo, principalmente devido aos modelos de geração de viagens adotados. Além disso, os estabelecimentos atacadistas são em menor proporção e descentralizados na cidade, geralmente localizados próximos aos principais eixos viários, enquanto o varejo se distribui por toda a cidade, mas tem maior proporção na área central. Logo, como os dados de referência são relativos à área central, o fato de não modelar a cadeia completa não inviabilizaria a análise dos resultados e, então, priorizou-se avaliar o fluxo de entrega aos estabelecimentos varejistas.

A base de dados secundários utilizada foi o Cadastro Municipal de Contribuintes de Tributos Mobiliários - CMC atualizado em 2011, fornecido pela Prefeitura de Belo Horizonte. Trata-se do cadastro de pessoas jurídicas que exercem atividades no município de Belo Horizonte, sujeitas ao pagamento do Imposto Sobre Serviços de Qualquer Natureza - ISSQN ou das Taxas Mobiliárias (Taxa de Fiscalização, Localização e Funcionamento, Taxa de Fiscalização Sanitária e Taxa de Fiscalização de Engenhos de Publicidade).

\subsection{Geração de viagens e modelagem para distribuição}

Devido à impossibilidade de se usar os dados de uma pesquisa por questionário, foram levantados estudos anteriores sobre geração de viagens de transporte de cargas que usassem como variável explicativa do modelo a área e o tipo do estabelecimento. Considerando critérios como contexto em que os estudos foram desenvolvidos, proximidade à realidade brasileira e parâmetros utilizados compatíveis com os dados disponíveis, foram selecionadas as equações utilizadas.

Foram adotadas as equações de Melo e Campos (2003) e Tadi e Balbach (1994) citadas por Souza et al. (2010). Tadi e Balbach (1994) estudaram as viagens geradas pelo setor atacadista, importante para a dinâmica de distribuição de cargas. As equações encontradas por Melo e Campos (2003) foram adotadas nesse trabalho por diversos fatores, tais como o trabalho ser sido desenvolvido para o contexto brasileiro, portanto, mais próximo à nossa realidade, e adotar como variável a área do estabelecimento, dado disponível para esse estudo, conforme apresentado na Tabela 1. 
Tabela 1 - Equações utilizadas para geração de viagens ${ }^{4}$

\begin{tabular}{|l|l|l|}
\hline \multicolumn{1}{|c|}{ Variáveis dependentes } & \multicolumn{1}{c|}{ Variáveis independentes } & \multicolumn{1}{c|}{ Equação } \\
\hline $\begin{array}{l}\text { Geração de viagens de carga } \\
\text { para o setor atacadista* }\end{array}$ & $\mathrm{X}=1.000 \mathrm{~m}^{2}$ de área construída & $\mathrm{Y}=4,0 \mathrm{X}$ \\
\hline Supermercado** & $\mathrm{X}=$ Área construída de cada empreendimento & $\mathrm{Y}=1,1522+0,0012 \mathrm{X}$ \\
\hline Bar/Restaurante** & $\mathrm{X}=$ Área construída de cada empreendimento & $\mathrm{Y}=1,3334+0,0019 \mathrm{X}$ \\
\hline
\end{tabular}

No caso do setor atacadista, a equação é genérica para todo tipo de mercadoria, não se ajustando aos setores de alimentos e bebidas. Nesse caso, foi aplicado um fator de ajuste aos valores fornecidos pela equação. O fator de ajuste foi obtido considerando os dados da pesquisa de Oliveira (2014), que revelou que 31\% das entregas realizadas na área central de Belo Horizonte são provenientes de Belo Horizonte. Portanto, utilizou-se como premissa que o total de viagens produzidas em Belo Horizonte deve corresponder a $31 \%$ das viagens atraídas. Os resultados obtidos utilizando as equações foram compatíveis com os questionários considerados válidos.

A etapa de distribuição de viagens foi realizada utilizando os softwares TRANUS@ e TRANSCAD@. O TRANUSC calcula a distribuição de viagens através do modelo da Máxima Entropia. A distribuição espacial da demanda de uma área de consumo para as zonas de produção é feita utilizando o modelo logit em que a função de utilidade inclui o preço do setor que é demandado e, a desutilidade de transporte entre as duas zonas. Podem-se adicionar fatores atraentes para a distribuição, que pode incluir qualquer variável definida no modelo e parâmetros exógenos não modelados para representar elementos que afetam a distribuição (por exemplo, fatores ambientais). Como resultado do processo de localização de atividades se obtém um conjunto de matrizes de fluxos entre os setores transportáveis. Na interface atividades/transporte deriva-se a demanda de transporte, partindo dos fluxos socioeconômicos, obtendo-se a matriz de viagens. Após a distribuição, a matriz de demanda de viagens por categoria de usuário foi alocada na rede multimodal de transporte com um modelo logit em que o custo generalizado é a função de utilidade.

$\mathrm{Na}$ aplicação feita para esse estudo, foi simulado apenas o fluxo de cargas, não sendo considerados dados de transporte de passageiros. Essa simplificação incorre no risco de não se considerar ocorrência de congestionamentos durante a alocação, o que reduz a impedância e

\footnotetext{
${ }^{4}$ Fonte: Autores, baseado em * Tadi e Balbach (1994) e ** Melo e Campos (2003)
} 
distorce o resultado. Para reduzir esse impacto negativo, devem ser atribuídos fatores de penalidade aos links, proporcionalmente ao nível de serviço dos mesmos. A identificação do grau de saturação dos links deve ser feita por meio de diagnósticos realizados em outros estudos. Caso não esteja disponível essa informação, recomenda-se não desconsiderar o transporte de passageiros na simulação. Além disso, não era objetivo desse estudo avaliar impactos ou políticas de uso do solo, portanto, esse setor não foi considerado.

\subsection{Resultados}

Como resultado da etapa de geração de viagens, a concentração de viagens produzidas e atraídas foi analisada. Para efeito de comparação entre zonas, foi feita uma normalização pela área de cada zona. Observa-se, com auxílio da Figura 4, que as zonas que mais atraem viagens, proporcionalmente, estão localizadas na área central do município, o que se explica pela elevada representatividade em termos de comércio existente nessa área. Destacam-se também a região de Venda Nova e, em números absolutos, o Barreiro, que vêm se consolidando como centros regionais ao longo das últimas décadas.

Em relação à produção de viagens, considerando as zonas internas de Belo Horizonte, destaca-se a área do entorno da Avenida Antônio Carlos, e áreas pericentrais, com destaque também para a região Oeste, de maneira geral, e a região ao norte da Lagoa da Pampulha, se estendendo à Venda Nova.

Para efeito da modelagem, na etapa de distribuição, como dito anteriormente, os resultados de Oliveira (2014) foram utilizados para as estimativas de produção de viagem dos demais municípios da Região Metropolitana. Como o número total de viagens geradas foi estimado e o dado de entrada no software já se refere às próprias viagens, foi considerada a princípio uma elasticidade da categoria de transporte nula, de modo que todas as viagens produzidas ocorressem entre zonas. O ajuste da elasticidade permitiria considerar uma proporção de viagens intrazonais, não simuladas. No entanto, devido às características do município no qual foi feita a aplicação, optou-se por desprezar a ocorrência de viagens internas às zonas. Como foi possível observar pelos resultados da etapa de geração de viagens, a maior parte das viagens com destino ao município, se originam em outros municípios, sendo zonas externas à área de planejamento. Em relação às viagens que se originam em Belo Horizonte, observa-se uma concentração em poucas zonas, sendo que uma maior ocorrência de viagens internas se 
restringe a essas poucas zonas. Para as zonas da área central, foco da pesquisa de campo de referência, esse efeito é reduzido, pois além de terem baixa produção de viagens, são zonas de menor extensão.



Figura 4 - Viagens atraídas e produzidas por unidade de área, no município de Belo Horizonte ${ }^{5}$

Comparando os resultados obtidos pelo modelo com os resultados de Oliveira (2014) observase uma coerência, uma vez que os bairros identificados como origens mais importantes pela pesquisa de campo se situam, em sua maioria, na porção centro-oeste do município, e ao longo da Avenida Antônio Carlos, como o bairro São Francisco, Caiçaras (zona 17), Pampulha (zonas 22, 23, 24), Carlos Prates (zona 18) e Anel Rodoviário (zonas 14,17, 19). Além disso, destaca-se o fato de a pesquisa de Oliveira (2014) ter sido feita no perímetro da área central, o que inviabiliza a coleta de dados cujo trajeto entre origem e destino não atravesse a região central. Visto a importância do município de Contagem como origem das viagens, é possível que alguns destinos importantes não tenham sido captados na pesquisa.

\footnotetext{
${ }^{5}$ Fonte: Autores
} 
Outro ponto de ressalva, é que o estudo de Oliveira (2014) considerou vários outros setores além de bebidas e alimentos, o que evidentemente impede uma comparação rigorosa dos resultados.

De modo a permitir uma comparação entre os dados da pesquisa de referência e a matriz OD estimada, os dados foram agregados conforme o zoneamento proposto, sendo que as zonas 1 a 9 foram agrupadas constituindo a área central. Além disso, o percentual foi calculado considerando o total de viagens com origem em Belo Horizonte, assim como os dados de referência. Para obter os dados relativos somente os segmentos de alimentos e bebidas, o dado total foi corrigido. Essa correção levou em conta a proporção do número de estabelecimentos atacadistas relacionados a alimentos e bebidas em relação ao total de atacadistas em cada zona. A Tabela 2 mostra a comparação dos resultados.

A análise de correlação entre as duas colunas, excluindo-se a linha "Outros", revela um índice de 0,81. A linha "Outros" não deve ser incluída na análise comparativa, pois agrega zonas com características distintas, e não permite uma comparação direta de par OD. A análise de correlação é usada para examinar cada par de variáveis de medida e determinar se as duas variáveis tendem a se mover juntas, ou seja, se os valores altos de uma variável tendem a ser associados aos valores altos da outra (correlação positiva), se os valores baixos de uma variável tendem a ser associados aos valores altos da outra (correlação negativa) ou se os valores das duas variáveis tendem a não se relacionar (correlação próxima de zero). O resultado indica uma alta correlação positiva, indicando uma coincidência entre a hierarquia das origens. 
Tabela 2 - Principais origens, em Belo Horizonte, das viagens de carga com destino à área central ${ }^{6}$

\begin{tabular}{|c|c|c|}
\hline Zona & Referência Ajustada & OD Calculada \\
\hline Área central & $2,9 \%$ & $7,6 \%$ \\
\hline 17 & $3,4 \%$ & $5,6 \%$ \\
\hline 18 & $0,8 \%$ & $2,6 \%$ \\
\hline 22 & $3,0 \%$ & $3,6 \%$ \\
\hline 23 & $2,6 \%$ & $3,7 \%$ \\
\hline 25 & $0,5 \%$ & $0,5 \%$ \\
\hline 27 & $10,2 \%$ & $9,7 \%$ \\
\hline 28 & $6,7 \%$ & $5,0 \%$ \\
\hline 29 & $2,0 \%$ & $3,1 \%$ \\
\hline \multicolumn{2}{|c|}{ Correlação } & $\mathbf{0 , 8 1}$ \\
\hline Outros & $68 \%$ & $59 \%$ \\
\hline
\end{tabular}

O gráfico de dispersão dos resultados, Figura 5, revela $\mathrm{R}^{2}=0,6526$, compatível com modelos estudados anteriormente apresentados na Seção 1. Porém ressalta-se a dificuldade de comparação dos resultados estimados em função dos problemas relacionados à escassez de dados primários válidos, o que limita o tamanho da amostra. A calibração por meio de contagem volumétrica permitiria melhorar essa correlação.

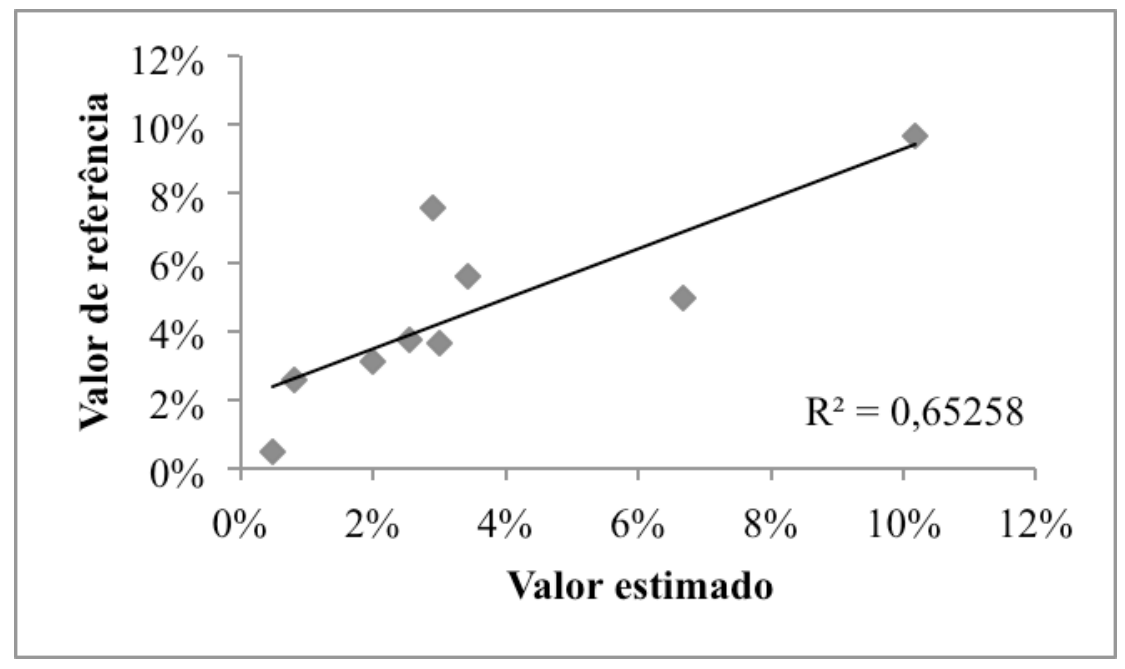

Figura 5 - Dispersão dos resultados ${ }^{7}$

A Figura 6 apresenta o mapa das linhas de desejo, com o resultado obtido para a etapa de distribuição. As linhas conectam zonas de origem e destino, e a espessura representa o

\footnotetext{
${ }^{6}$ Fonte: Autores

${ }^{7}$ Fonte: Autores
} 
número de viagens entre o par de zonas. Observa-se que as principais trocas se realizam com o município de Contagem, nesse caso representado por uma única zona. De acordo com o estudo de Oliveira (2014), cerca de 37\% das cargas transportadas em Belo Horizonte têm origem em Contagem. Essa elevada proporção se explica pela concentração de indústrias nesse município, além da localização da Central de Abastecimento CEASA Minas.



Figura 6 - Linhas de desejo ${ }^{8}$

Internamente ao município de Belo Horizonte, observa-se a área central (zonas 1 a 9) com importante número de trocas, destacando-se dentre os destinos, e também os centros regionais Venda Nova (zonas 28 e 30) e Barreiro (zona 27).

O cálculo do número de veículos que realizam as entregas diariamente considerou que um mesmo veículo realiza mais de uma entrega por dia. Para esse cálculo, considerou-se o valor encontrado na pesquisa de Oliveira (2014), de que são realizadas em Belo Horizonte, em

\footnotetext{
${ }^{8}$ Fonte: Autores
} 
média, 25 entregas diárias por caminhão. Foi encontrado o valor de 630 veículos para realizar as entregas no município de Belo Horizonte.

Em relação ao total de veículos encontrado, foram pesquisados dados municipais que permitissem uma comparação. Segundo dados do Plano de Mobilidade Urbana de Belo Horizonte - PlanMob-BH, realizado pela BHTRANS, apresentado em 2011, Belo Horizonte apresenta uma movimentação diária de 19 mil viagens de caminhões, sendo a maioria delas viagens de atravessamento, que não têm como destino o município. Dessas viagens, 2.029 são destinadas a Belo Horizonte. A Tabela 3 apresenta os dados do PlanMob (BHTRANS, 2010).

Tabela 3 - Origem e destino das viagens realizadas por caminhão9

\begin{tabular}{|l|c|c|c|c|}
\hline Origem \Destino & Belo Horizonte & Região Metropolitana & Outros & Total \\
\hline Belo Horizonte & 5 & 56 & 1.570 & 1.631 \\
\hline Região Metropolitana & 67 & 299 & 4.985 & 5.351 \\
\hline Outros & 1.957 & 4.158 & 5.968 & 12.078 \\
\hline Total & 2.029 & 4.513 & 12.523 & 19.060 \\
\hline
\end{tabular}

Cruzando essas informações, com os dados levantados por Oliveira (2014), tem-se que $42 \%$ das viagens são devidas ao transporte de alimentos e bebidas na área central. Expandindo-se essa proporção para o município, equivale a 852 viagens. $\mathrm{O}$ valor encontrado para as viagens atraídas corresponde a 74\% desse total, o que mostra um ajuste razoável do modelo utilizado. Cabe ressaltar, que a área central do município concentra $20 \%$ do número total de entregas de alimentos e bebidas calculadas para Belo Horizonte, em uma área que representa apenas 3,3\% da área do município. Logo, a proporção de $42 \%$ pode estar superestimada considerando o município como um todo, havendo uma maior correspondência entre o valor calculado e o dado de referência. Reforça-se a importância da calibração com dados de contagens volumétricas atualizadas.

Em relação ao carregamento da malha viária, realizado pelo software TRANUS@, as vias mais carregadas foram Avenida Amazonas, Via Expressa, Anel Rodoviário, Antônio Carlos e Cristiano Machado, como é possível observar na Figura 6, o que coincide com as vias principais identificadas como trajeto dos veículos da pesquisa de Oliveira (2014).

\footnotetext{
${ }^{9}$ Fonte: Autores, baseado em BHTRANS (2010)
} 
Os resultados encontrados se mostram coerentes, dentro dos limites em que é possível comparar com dados de campo. Apesar de não ter sido realizada a última etapa de calibração dos volumes, foi possível avaliar a matriz OD estimada, que alcançou um bom ajuste para modelos baseados apenas em dados secundários.

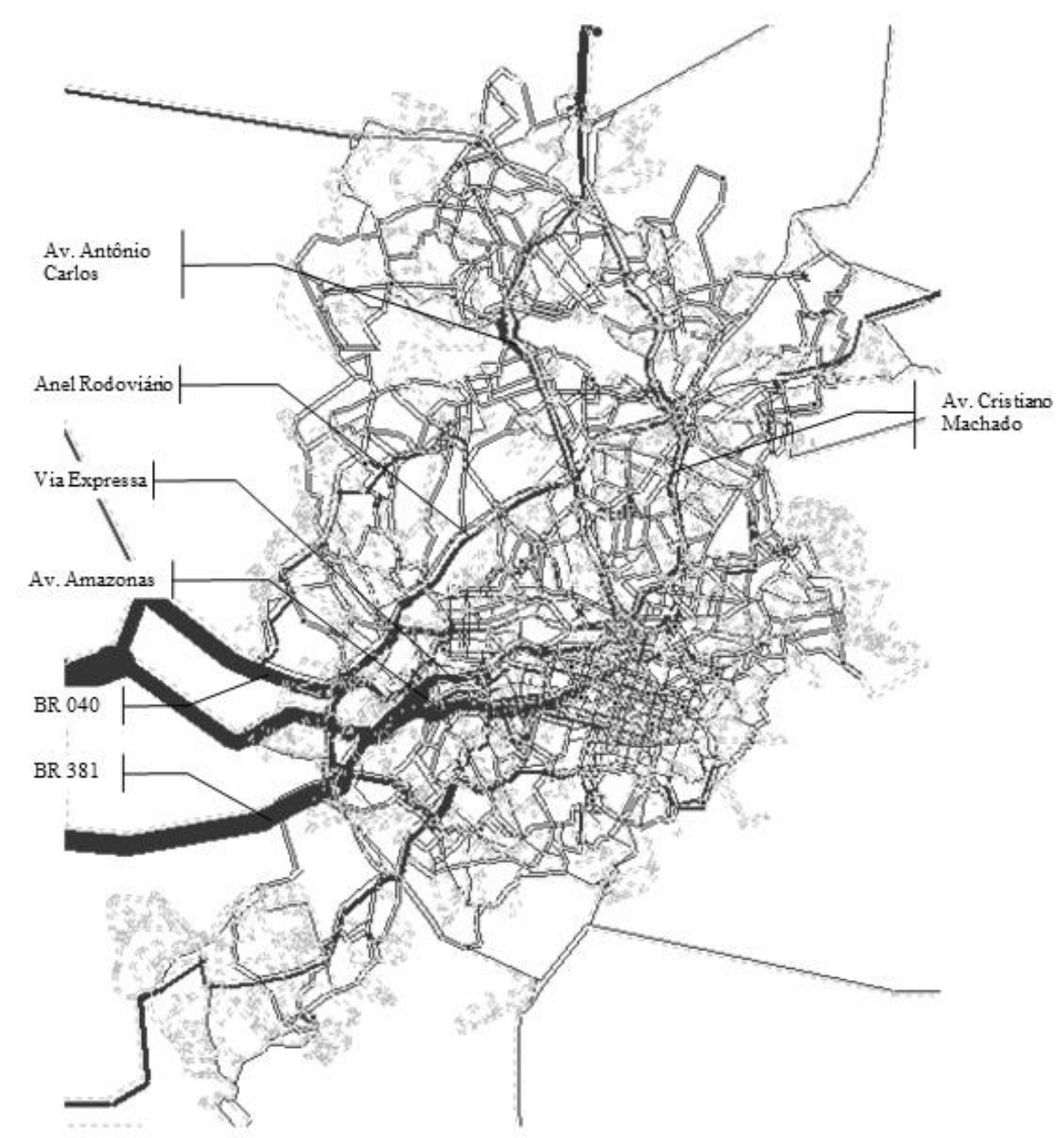

Figura 7 - Carregamento da distribuição de cargas dos setores alimentos e bebidas em Belo Horizonte ${ }^{10}$

O princípio utilizado para a distribuição das viagens se baseia na relação de produção e consumo derivada das atividades desenvolvidas em locais geograficamente identificados. Esse princípio se mostra bastante consistente para a análise dos fluxos de carga, analisados por segmento econômico, uma vez que é possível identificar objetivamente os

${ }^{10}$ Fonte: Autores 
estabelecimentos comerciais envolvidos na dinâmica de fluxos, e de se trabalhar com uma amostra muito completa, abarcando praticamente todos os estabelecimentos comerciais do município.

Devido à indisponibilidade de dados de contagem volumétrica atualizados para esse estudo, não foi possível realizar o último passo da metodologia proposta, que se refere justamente ao ajuste dos volumes calculados em relação aos volumes verificados em campo. Em contrapartida, as etapas propostas para realização desse ajuste são consolidadas e amplamente conhecidas na Literatura, através da utilização de softwares específicos. Ressalta-se que o software TRANUS@ não permite fazer esse ajuste internamente, portanto os dados devem ser trabalhados com auxílio de outro software.

Os dados conhecidos de volumes são relativos ao município como um todo, não sendo específicos para os setores analisados, dificultando análise comparativa dos resultados. Ainda assim, é possível avaliar a adequação do modelo de geração de viagens utilizado, que se mostrou adequado ao município de Belo Horizonte. Nesse estudo, foram utilizados modelos já reconhecidos na Literatura, e foi sugerida uma pesquisa complementar, para os casos em que o modelo não se ajustar corretamente.

\section{Conclusão}

Entender a dinâmica dos fluxos de mercadorias se torna cada vez mais importante para a implantação de políticas públicas relacionadas à Logística Urbana. Os instrumentos de planejamento que podem auxiliar no processo de planejamento, como a matriz OD, são tradicionalmente dispendiosos, e requerem um prazo relativamente grande de execução. Nesse contexto, o trabalho propôs uma metodologia para estimar uma matriz OD de cargas a partir de três variáveis (localização, atividade, e variável explicativa do modelo de geração de viagens) obtidas a partir do cadastro municipal de contribuintes. Essa metodologia, composta de sete etapas (definição da área de estudo, zoneamento, escolha dos segmentos econômicos, coleta e tratamento de dados secundários, geração de viagens, modelagem da distribuição e calibração) foi aplicada à Belo Horizonte, e os resultados comparados aos dados de referência do estudo de campo elaborado por Oliveira(2014). 
Pesquisas para o desenvolvimento de métodos alternativos aos tradicionais apresentam uma grande relevância, pois podem permitir o avanço nas discussões de políticas de planejamento, sem requerer um investimento financeiro tão significativo. A metodologia proposta contribui para esse desenvolvimento ao ampliar as opções de ferramentas para o planejamento, menos dependentes de aquisição de dados primários, os quais são de difícil obtenção.

Além disso, a forma como a metodologia foi proposta, tendo como dado de entrada a utilização de uma base do cadastro municipal, permite sua aplicação para outros municípios e outros segmentos de carga, uma vez que esse tipo de base reúne informações sobre diversos segmentos. No entanto, a aplicação da metodologia requer alguns cuidados, uma vez que a qualidade dos resultados está diretamente ligada à qualidade da base de dados utilizada. Deve ser dada devida atenção às limitações dos dados em relação ao segmento em análise. Nesse estudo, foram considerados os segmentos de bebidas e alimentos, sendo analisados estabelecimentos atacadistas e de produção alimentícia, associados à produção, e estabelecimentos como bares, restaurantes, supermercados e comércio de produtos alimentícios, como consumidores. Trata-se de estabelecimentos em que o consumo acontece no local do estabelecimento, e o dado de área, utilizado na etapa de geração de viagens, encontra-se associado ao local do estabelecimento. Para determinados segmentos, pode haver distorções em relação à base de dados e à dinâmica de consumo, como por exemplo, no setor da construção civil. Para esse setor, o dado de área está relacionado à sede da construtora, e não ao local onde efetivamente está ocorrendo a obra.

Em relação aos modelos de atividades, o estudo apresenta uma ampliação das possibilidades de aplicação para avaliação de fluxos de cargas. Esses modelos se mostram coerentes e relevantes para fluxos logísticos, uma vez que o foco passa a ser identificar as relações geradoras da demanda de transporte, variáveis de acordo com o segmento. Isso permite que a dinâmica de transporte de carga seja vista como parte do contexto urbano, determinada pelas relações urbanísticas, e não mais como um sistema isolado. Essa visão sistêmica contribui para o planejamento integrado da cidade, incorporando suas diversas dimensões.

Algumas considerações podem ser feitas em relação a novas aplicações da metodologia proposta e desenvolvimento de futuros trabalhos. O resultado final pode ser melhorado a partir da integração de outros segmentos e de dados de contagem volumétrica classificada, viabilizando um ajuste final da matriz OD a partir da alocação. 
A aplicação realizada teve como foco o canal de distribuição entre atacadistas e varejistas devido a limitações dos modelos de geração adotados. No entanto, a base de dados permite estruturar a cadeia completa, o que se recomenda para futuros trabalhos.

Outra questão relevante que não foi abordada no estudo e merece uma investigação mais criteriosa é a inclusão do uso do solo na modelagem. Essa investigação é extremamente pertinente, uma vez que, em função da flexibilização de parâmetros de uso do solo, se tem observado um processo de desconcentração de atividades, impactando na dinâmica de distribuição de mercadorias.

\section{Referências}

Almeida, A. M. P. (1999) Sistemas de canais de distribuição: um estudo de caso na indústria alimentícia mineira. Caderno de pesquisa em administração, vol. 1, n. 8, São Paulo.

Ambite, J. L., Giuliano, G., Gordon, P., Pan, Q. e Bhattacharjee, S. (2003) Integrating heterogeneous data sources for better freight flow analysis and planning. Transportation Research Board Annual Meeting. Washington.

Bandeira, J. M., Coelho, M. C., Sá, M. E., Tavares, R. C., Borrego, C. (2011) Impact of land use on urban mobility patterns, emissions and air quality in a portuguese medium-sized city. Science of the total environment vol. 409, n. 6, pp.1154-63.

Cascetta, E. (2001) Transportation systems engineering: theory and methods. Norwell: Kluwer Academic Press.

Chatterjee, A., Wegmann, F. J., Brogan, J. D. e Phiu-Nual, K. (1979) Estimating truck traffic for analyzing UGM problems and opportunities. ITE Journal, vol. 49, n. 5, pp. 24-31.

Christiansen, D. F. (1979) Urban transportation planning for goods and services. Documento de trabalho - Texas Transportation Institute (não publicado).

De La Barra, T. (2012) Formulación matemática de TRANUS. Documento de trabalho - Modelística (não publicado). Disponível em www.modelistica.com.

Dutra, N. G. S. e Novaes, A. G. N. (2005) Distribuição de encomendas em centros urbanos baseada no enfoque de city logistics. XIX Congresso de Pesquisa e Ensino em Transportes, vol. 2, pp. 1724-1735.

Empresa de Transporte e Trânsito de Belo Horizonte - BHTRANS (2010) Plano de mobilidade urbana de Belo Horizonte. Texto não publicado. Disponível em www.bhtrans.pbh.gov.br.

Holguin-Veras, J., Jaller, M., Destro, L., Xuegang, B., Lawson, C. e Levinsosn, H. S. (2011) Freight generation, freight trip generation, and the perils of using constant trip rates. Journal of the Transportation Research Board, vol. 2224, pp. 68-81.

Instituto Brasileiro de Geografia e Estatística - IBGE (2010) Censo demográfico. Brasil.

Iding, M. H. E., Meester, W. J. e Tavasszy, L. A. (2002) Freight trip generation by firms. 42nd European Congress of the Regional Science Association, Dortmund. 
Gasparini, A. e Campos, V. B. G. (2009) Uma análise da geração de viagens de veículos de carga para shopping-centers. XXIII Congresso da Associação Nacional de Pesquisa e Ensino em Transporte, Vitória.

Lawson, C., Holguín-Veras, J., Sánchez-Díaz, I., Jaller, M., Campbell, S. M. S. e Powers, E. L. (2012) Estimation of freight trip generation based on land use. Transportation Research Board Annual Meeting, Boston.

Marra, C. (1999) Caracterização de demanda de movimentações urbanas de carga. Dissertação de Mestrado em Engenharia Civil, Universidade Estadual de Campinas, São Paulo.

Melo, I. C. B. e Campos, V. B. G. (2003) Uma proposta para modelagem da demanda de transporte de carga em área urbana. XIV Congresso Brasileiro de Transporte e Trânsito, Vitoria.

Munuzuri, J., Cortes, P., Onieva, L. e Guadix, J. (2009) Modeling freight delivery flows: missing link of urban transport analysis. Journal of Urban Planning and Development, vol. 135, n. 3, pp. 91-99.

Nguyen-Luong, D. (2008) An integrated land use-transport model for the Paris Region (SIMAURIF): Ten lessons learned after four years of development. Documento de trabalho - Institut d'aménagement et d'urbanisme de la région Ile-de-France - IAURIF (não publicado).

Ogden, K. W. (1992) Urban goods movement: a guide to policy and planning. Inglaterra: Editora Ashgate.

Oliveira, L. K. (2014) Diagnóstico das vagas de carga e descarga para a distribuição urbana de mercadorias: um estudo de caso em Belo Horizonte. Journal of Transport Literature, vol. 8, n. 1, pp. 178-209.

Ortúzar, J. D. e Willumsen, L.G. (1990) Modelling transport. England: John Wiley and Sons Ltd.

Pagliara, F., Reale, A. e De La Barra, T. (2009) Integrated land use/transport models for evaluating land use impact. XVI International Conference SIDT2009 Transport management and land-use effect in presence of unusual demand, Milan.

Parsons Brinckerhoff Quade (1999) Development and calibration of the statewide land use-transport model. Documento de trabalho - Transportation and Land Use Model Integration Program Phase II (não publicado).

Silva, J. e Waisman, M. R. (2007) Cargas urbanas: estudo exploratório sobre a geração de viagens de caminhões em bares e restaurantes. $16^{\circ}$ Congresso da ANTP, Maceió.

Souza, C. D. R., Silva, S. D. e D'agosto, M. A. (2010) Modelos de geração de viagens para polos geradores de viagens de cargas. Transportes, vol. 18, n. 1, pp. 46-57.

Souza, C. D. R., Silva, S. D. e D'agosto, M. A. (2013) Modelo de quatro etapas aplicado ao planejamento de transporte de carga. Journal of Transport Literature, vol. 7, n. 2, pp. 207-234.

Tadi, R. R. e Balbach, P. (1994) Truck trip generation characteristics of nonresidential land uses. ITE Journal, vol. 64, n. 7, pp. 43-47.

Vichiensan, V., Sato, K., Miyamoto, K. e Kitazume, K. (2003) Introduction of land use model to improve travel demand forecasting in a metropolitan area: A case of Tranus application to Sapporo. Journal of the Eastern Asia Society for Transportation Studies, vol. 5. pp. 2863-2871.

Zavattero, D. A. e Weseman, S. E. (1993) Commercial vehicle trip generation in Chicago region. Transportation Research Record, vol. 60, n. 12, pp. 12-15.

Zonnenberg, R. (1989) De verkeersproductie van bedrijventerreinen. Breda: Hogeschool voor toerisme en verkeer. 